\title{
Developing A Virtual Reality Application of Pathok Negoro Mosque for Digital Conservation
}

\author{
Endang Setyawati ${ }^{1}$, Adwiyah Asyifa $^{1}$, Hendro Trieddiantoro Putro ${ }^{1^{*}}$, Mohammad Ischak $^{2}$ \\ ${ }^{1}$ University Technology of Yogyakarta, Yogyakarta, Indonesia, \\ ${ }^{2}$ Trisakti University, Jakarta, Indonesia
}

*Corresponding e-mail: hendro.putro@staff.uty.ac.id

\author{
Article info: \\ Received: 29-07-2019, Revised: 09-09-2019, Accepted: 03-10-2019
}

\begin{abstract}
In the last decades, new technologies have developed and used for digital conservation. Nowadays, virtual reality is becoming an instrument applicable to many areas of science and visual communication. Pathok Negoro Mosque is one of the Javanese Islamic mosque buildings that built in the 1700s. The building of this mosque still exists. Pathok Negoro Mosque several times has changed the shape and architecture of the building. The mosque established during the reign of Sultan Hamengku Buwana I. The Mosques has an extraordinary concept and philosophy. This project was an archiving of space so we can preserve in a virtual environment. In this paper, we will present the process of the VR app making also describe the benefits and challenges associated with this approach. The method was by research and development by prototyping the building in 3D model, then providing virtual tours in different place and times. This paper will discuss the VR issue focusing on several hardware devices and software platforms for digital content management. This case study allowing a better understanding of Pathok Negoro Mosques history and atmosphere. The analyzed virtual experience proved to be advantageous in delivering tangible and intangible information.
\end{abstract}

Keywords: Digital Conservation, Virtual Reality, 3D Model, Virtual Experience

\section{Introduction}

\subsection{Pathok Negoro Mosque}

Pathok Negoro Mosque is one of the Javanese Islamic mosque buildings that built in the 1700s. The building of this mosque still exists. Pathok Negoro Mosque several times has changed the shape and architecture of the building. The mosque, which established during the reign of Sultan Hamengku Buwana I, has an extraordinary concept and philosophy. In addition to being a place of worship, the mosque also used as the boundary and periphery of the Islamic Mataram kingdom of Yogyakarta. This mosque was part of the political strategy of Sultan Haemngku Buwana I to defend the country from Dutch colonialism at that time. This spirit of resistance to the Netherlands underlies the concept of the existence of Pathok Negoro Mosque. His physical appearance with Javanese building architecture shows the philosophical meaning of the triumph of the Javanese Islamic empire in Yogyakarta. The mosque as a form of embodiment of Islam is embodied in the strategic concept of the state, based on consideration of the security situation at that time.

The parts of the Pathok Negoro mosque are designed with concepts and have specific meanings. For example, the existence of a pool around the foyer building has a particular meaning from the design concept. The use of Sokoguru as the main structure of the mosque also has concepts and meanings. The use of the Tajug roof is composed of two or three, and also the appearance of the building and the atmosphere made in the main building, the building part of the foyer, the hall and the courtyard of the mosque have defined concepts and meanings. 
Pathok Negoro Mosque as a historical building is inseparable from the development of its society which continues to grow following the times, science and technology. The younger generation who do not understand the existence of the Pathok Negoro mosque as a historical building with high philosophical value assisted in having a different understanding of the concept of the Pathok Negoro mosque and its establishment. This crisis of understanding will affect the existence of the Pathok Negoro mosque. Efforts are needed to maintain the existence of this historic mosque and the effort to maintain an understanding of the concept of the Pathok Negoro mosque.

To be able to appreciate the conditions and atmosphere of the Pathok Negoro mosque as one of the historical buildings that have the meaning and philosophy of the Indonesian nation, it takes a medium to experience that able to see and feel the atmosphere of the mosque in Pathok Negoro mosque. Physical documentation that has made so far is less able to fulfill the purpose of understanding. By utilizing technological advances, identification, conservation, and preservation of historic buildings that have meaning can be done using Virtual Reality technology.

VR technology is an effort to document heritage buildings. This method is by documenting all parts of the building, both physical and atmospheric. So that readers can read and feel the entire building parts, have a visual and physical experience, and even feel and see the reconstruction of buildings or the parts of the building that have damaged, replaced or changed to the atmosphere and view that should be following the condition of the building concept.

Virtual Reality technology used in the conservation efforts of the building of Pathok Negoro mosque. Non-physical conservation by planning programs using Virtual Reality technology. This technology is designed not only to be able to see the physical structure but also to understand the meaning displayed in 3 dimensions. Virtual Reality, in general, is a simulation that is displayed through devices, with media in the form of computers and smartphones. Virtual Reality according to Mihelj (2014) is a concept of the artificial environment with immersive, interactive, insight, and high imagination levels, namely by replicating the environment and the capabilities of the human senses, so that virtual reality users can interact with objects in an artificial environment. The purpose of this research is to create a Virtual Reality application for conserving Pathok Negoro Mosque in Yogyakarta.

\subsection{Preservation and Conservation}

Preservation is an activity to preserve something for a specific purpose. Preservation activities interpreted as caring for or maintaining and rebuilding or rebuilding. So that Preservation can be interpreted as preserving an object, either by caring for it if the object is still intact according to the original and rebuilding the object if the object is damaged or completely gone. Preservation, namely all elements of management, finance, storage, tools, employment, and methods used to preserve library materials, documentation, archives, and the information they contain (Lasa, 2009).

According to Lasa HS (2019) in the Indonesian Librarian Dictionary, Conservation interpreted as follows: 1) policies and activities that include protecting library material from damage. This activity includes the methods and techniques used and carried out by technicians. Conservation activities that are usually carried out are densification, encapsulation, or lamination, making microfilms, digital or electronic storage; 2) the use of chemical or physical procedures in the maintenance and storage of libraries to ensure the durability of libraries.

Preservation aims to preserve the information contained in order to maintain historical building integrity. While conservation is more to the methods or techniques to protect it so that it is not easily damaged. 
Preserving aims to make an object to remain as it is to serve as a lesson, reference, or study with historical value. Some principles according to Cohen (2001) are the background of preservation and conservation activities, namely:

1) Physical Identity from the Area (Physical Identity of Environment).

2) Sense of Place. Historical relics are the only thing that connects with the past and connects us to a particular place.

3) Value of History (The Historical Values of the City District). In the course of the nation's history, there were significant events to be remembered, respected and understood by the community. Activities to maintain the environment and historical buildings that are part of the journey of history.

4) Elevate the Architectural Value of Buildings and the Environment. Maintaining the environment and historic buildings because of their intrinsic value as works of art in which there are high achievements in the arts, including beauty.

5) Economic benefits. Existing buildings, especially those with historical values often have economic advantages. Empirically shows that the use of existing buildings is often cheaper than making new buildings.

6) Generator for Tourism and Recreation activities. Typical historical values in a place or area can be an attraction for tourism activities and attract them to the place.

7) Source of Inspiration (Place of Inspiration). Many historical buildings relate to the sense of patriotism and the value of nationalism and essential events in the past.

8) Elevating Knowledge. Historical buildings and environments as artifacts can basically complete written documents about the past to commemorate certain events or events in the past.

\subsection{Virtual Reality Technology}

Mihelj (2014) in his book "Virtual Reality: Technology and Application" said that Virtual Reality is an interactive computer simulation that uses one or more tools as a replacement sensor for the human senses with the user's goal dissolving into a virtual environment.

Virtual Reality is a technology that is created so that users can interact with an environment simulated by a computer (Virtual Design Environment), an actual environment that is imitated or truly an environment that is only in imagination. Virtual Reality is the appearance of threedimensional images generated by a computer, which is evident with the help of a number of certain tools. The most important feature is to use a device designed for a specific purpose, this technology can make people who feel the virtual environment is fooled and convinced that what they are experiencing is real. Some of the most common Virtual Reality devices are:

1) Joysticks or gamepad

2) Force balls or tracking balls

3) Controller wands

4) Data gloves

5) Voice recognition

6) Motion trackers or bodysuits

7) Treadmills

Developed countries such as Europe have used Virtual-Reality technology for various purposes, including the preservation of historic buildings. Even development is very rapid for the tourism sector and architectural visualization (Daniel, 2010) (Putro, 2015) (Çizel, 2018) (Putro, 2018). 


\subsection{Virtual Reality for Digital Preservation and Conservation}

The preservation of buildings in a non-physical way using virtual reality technology has been done a lot. W.B. Yang et al. (2015) conducted a study by evaluating digital technology as a digital preservation tool for historic buildings in China. Who took the study of the Taipei Xia Hai City God Temple building and Dougong, focusing on the traditional Chinese wood connection structure technique. Yang and the team conducted several digital preservation methods between using Virtual Reality, Augmented Reality, and Digital Scanning technology. Ghadban (2013) along with a team of historians, archaeologists, and architects, reconstructed the ruins identified as the Hisham royal complex in Jericho Palestine in the Ummayad period of the early 8th century. The simulation shows its reconstruction in the form of a 3-dimensional environment with a middle eastern desert, where users can see the type of material, interact in a virtual environment by walking around the royal garden to enter into the royal room.

According to Ramzi Hassan (2016), researchers from NMBU who presented VR technology innovations at the UN seminar entitled peace in the Middle East, said that this technology could be used as an experimental tool that supports the process of investigating and documenting preservation - conservation, while increasing the sensitivity of the public against historic sites and easier to understand.

The city of Cluny in France is one example of a city that successfully utilizes Virtual Reality technology for the preservation of its historic buildings. Cluny is known as a medieval city of Roman heritage that has important sites for Europe and is protected by UNESCO. Funded by a European consortium and UNESCO, they designed a scenario that would enable everyone to project themselves in Cluny's history virtually. Cluny Abbaye is the largest cathedral in 11th century Europe which was primarily destroyed by World War II bombings. At present, for research purposes involving public participation and at the same time for tourism several screens are installed on the site, facing the object represented. The way it works is like presenting lost historical fragments with the concept of confrontation between the past and the present. Some points of view of buildings and urban areas that have been destroyed or changed over time, this screen can be returned to its original decoration.

\section{Method}

The research method is a research and development method of the Virtual Reality program with data analysis and survey techniques. This research divided into 3 stages. Phase 1 is the preparatory phase, which is carried out by a literature study on the building of the Pathok Mosque and by field observations for data collection, also photos of the Pathok Mosque building complex which is carried out periodically. Phase 2 is the analysis phase, analyzing to get the architectural characteristics, structure, and history of the building. Phase 3 is the synthesis stage, formulating an analytical framework to develop a Virtual Reality program.

\section{Discussion}

\subsection{Making Process}

The application making process begins with outlining the background of the Pathok Negoro mosque, the current condition, the importance of the mosque for the Yogyakarta Sultanate state in its existence as a defense pattern of the Yogyakarta Sultanate state territory. Furthermore, the search for the history of the Pathok Negoro mosque needs to be done indepth to get the condition and atmosphere of the mosque following the concept of building it. From the historical search results, there will be a change in physical and non-physical buildings. Survey to all Pathok Negoro Mosques was done to get the latest photos from the mosque building. 
The purpose of the direct survey is to get the characteristics of the architecture, structure, and history of the building. The Babadan mosque survey in Figure.3.1 was conducted during the day to get an overview of the material color and atmosphere of the mosque.

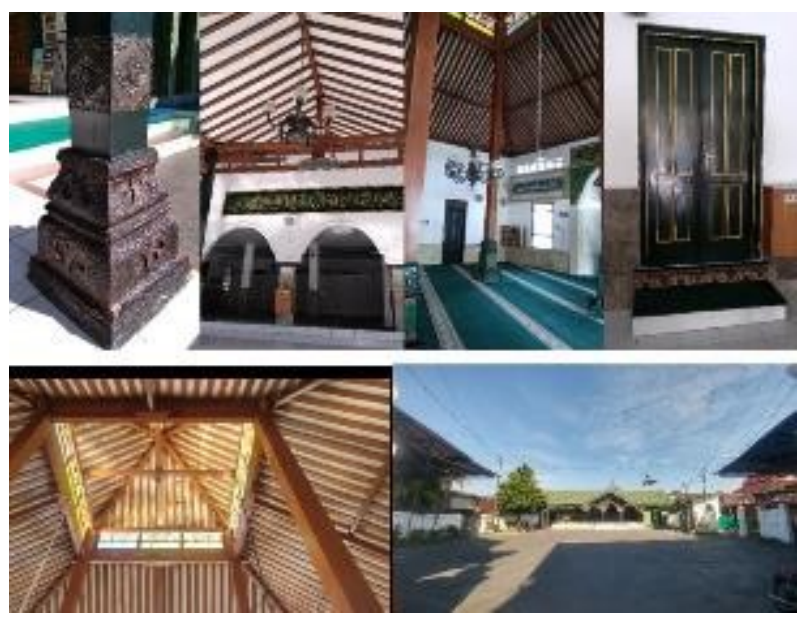

Figure 3.1. Photo Series of Babadan Mosque (Researcher, 2018)

The workflow Figure. 3.2 begins with creating a 2D plan, elevation, and a section of the building using AutoCAD. The process of making a 3D model is done using SketchUp software, then creating a virtual reality application using the Unity3D software. A similar workflow is carried out by Albourae, Armenakis, \& Kyan (2017), which starts with direct surveys and measurements, then the creation of virtual reality applications using Unity3D. However, to create 2d and 3D images using the BIM application. Different paths found by Deggim, Kersten, Tschirschwitz, \& Hinrichsen (2017), in which 3D objects obtained from a photogrammetry scan process, then the improvement of 3D object texture was made in 3D max software, and the creation of virtual reality applications using the Unreal Engine. Campbell (2017) explains in his thesis that unity3D and unreal engines are the two best software for developing virtual reality applications.

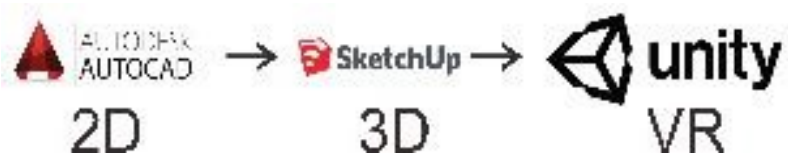

Figure 3.2. The Virtual Reality Application Workflow (Researcher, 2018)

\subsection{D Phase}

Conversion of Pathok Negoro mosque into $2 \mathrm{~d}$ digital images in Figure. 3.3 is done using AutoCAD software. This activity was carried out to bring up a picture of $2 \mathrm{~d}$ mosques that have a size and describe their structural elements, such as columns, walls, floors, windows, and roofs. 


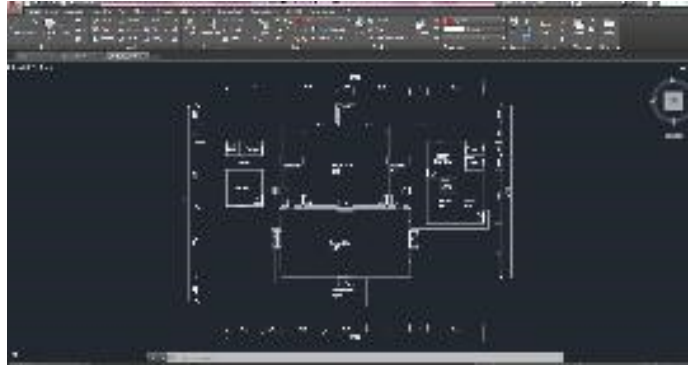

Figure 3.3. Dongkelan Mosque Plan in AutoCAD (Researcher, 2018)

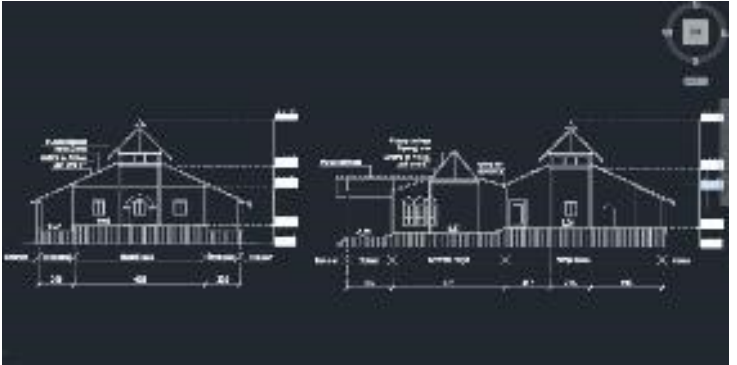

Figure 3.4. Dongkelan Mosque Section in AutoCAD (Researcher, 2018)

The obstacles in drawings at this stage are the lack of complete information obtained on the foundation structure and height of the building in Figure. 3.4 so that the interpretation step is carried out as an effort to bring up the image of the mosque's building structure. Information on the components of the mosque's roof structure in the form of Joglo is obtained through literature studies.

\subsection{D Phase}

The conversion of a 2D image of the Pathok Negoro mosque into a 3D digital model is done using Sketchup software. The 2D image that was previously done using AutoCAD is imported into Sketchup to make it easier to work on. The AutoCAD 2D image is a reference for projection in Figure. 3.5.

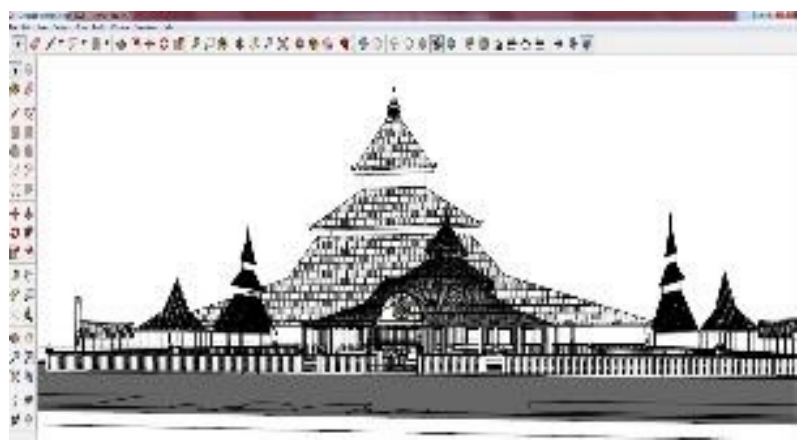

Figure 3.5. Projection of 2D Elevation from AutoCAD into Sketchup Software (Researcher, 2018)

The constraints on the construction in the 3-dimensional stage are the application of the logic of the roof structure, the connection system, the details of the ornaments and the determination of the material. The complexity of the roof structure of the mosque, thus giving rise to interpretations, especially on the roof connection and its structural components.

This 3-dimensional modeling phase is carried out in detail. The layer is used to facilitate and become a reference for the development of 3-dimensional models. The layer is adjusted to the number of buildings each mosque complex is created. The layer in Figure. 3.6 is the roof cover, roof structure, column structure, floors, walls, doors, and windows. 


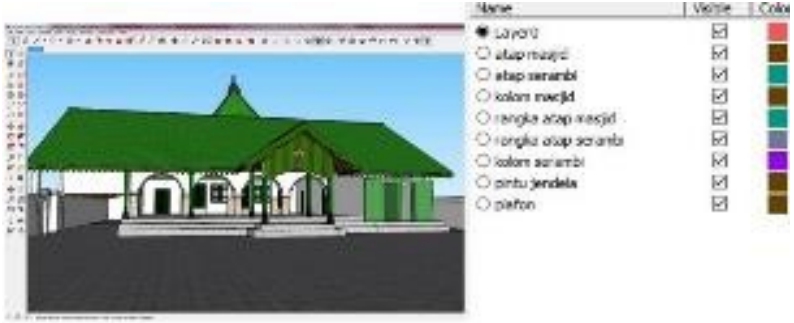

Figure 3.6. The Babadan Mosque 3D Modeling Process Using Sketchup (Researcher, 2018)

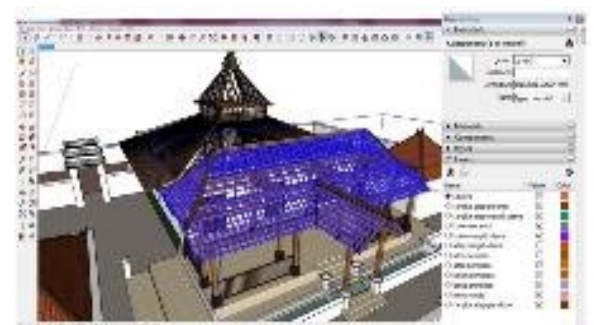

Figure 3.7. Layering, Grouping and Component Implementation in 3D Model of Mlangi Mosque in Sketchup (Researcher, 2018)

Grouping objects in Figure. 3.7 using component operations make it easy to work on 3D modeling, because of the same number of objects in terms of size and shape. The component operation makes it easy to edit multiple similar objects. The details of the ornaments and the color of the material Figure. 3.8 become a challenge at the stage of making the 3D mosque. The details of ornaments and colors show architectural characteristics and the unique atmosphere in each Pathok Negoro mosque. Interpretation technique used by the researcher as a method in the 3D model making phase, especially the details of ornament and colors. Sketchup basic material is used, and building color is matched using the sample paint tool in Sketchup to matched photos from observation. This method is time-consuming because of the lack of skill in 3D model making. Therefore, W.B. Yang (2015) and Deggim (2017) recommends to digitalized a building for preservation using photogrammetry method.
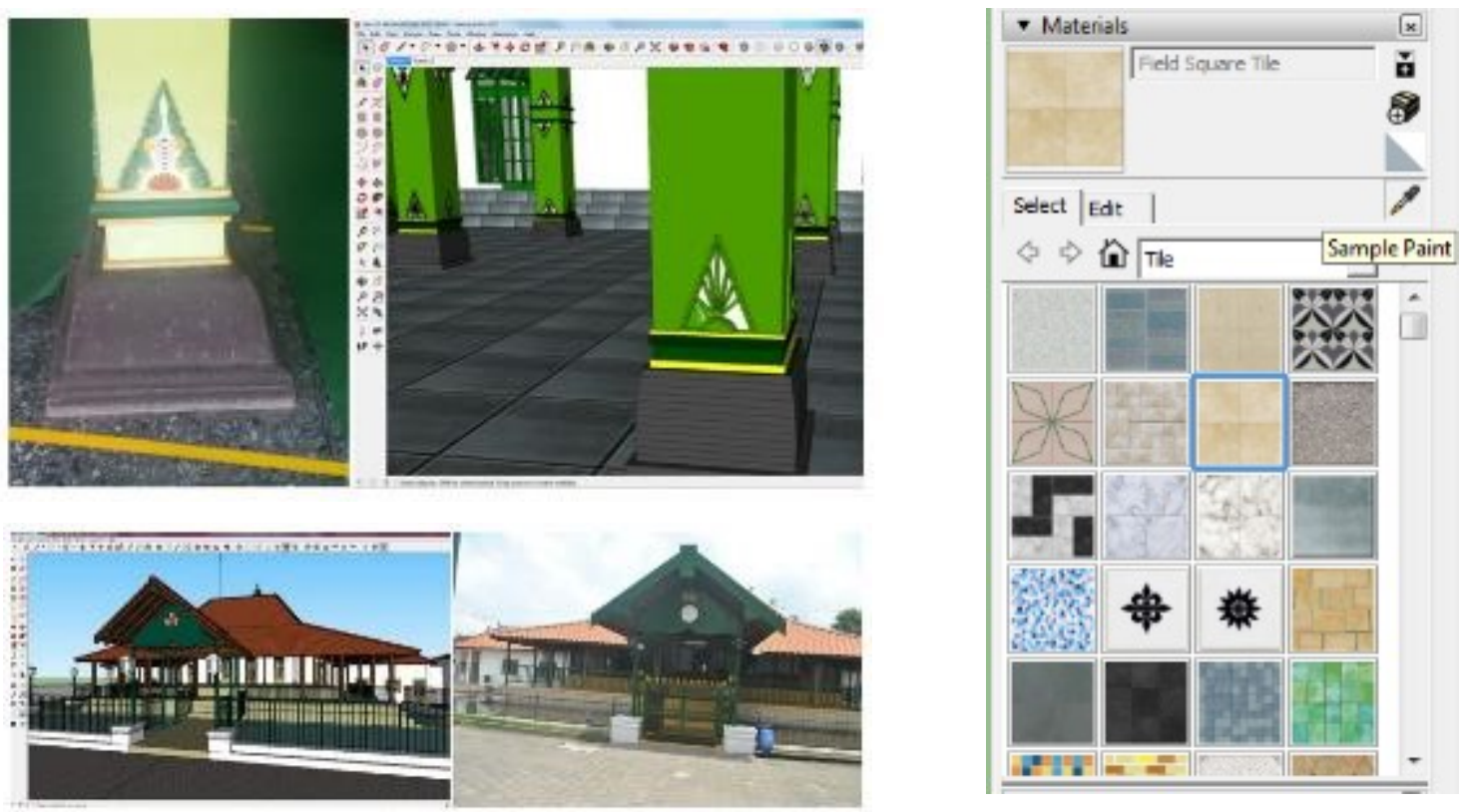

Figure 3.8. 3D Interpretation of Ornament Details and Material Color of Wonokromo and Plosokuning Mosque (Researcher, 2018)

\subsection{Virtual Reality Phase}

One of the advantages of unity3D is explained by Albourae, Armenakis, \& Kyan (2017), that this software accepts import objects from other applications. Unity3D accepts the model and texture of Sketchup in real-time, if objects and materials in the Sketchup changed, then the objects and materials in Unity3D will follow. In addition, the unity3D software can accept FBX file types which are strictly related to BIM or other 3D model software. 
In this study, 3D mosque objects from Sketchup are classified according to the category of structural elements such as roofs, roof structures, walls, and windows. Then the workflow in Figure 9. the Sketchup file is imported into the assets unity3D folder. This is done to facilitate editing of 3D objects on unity3D.

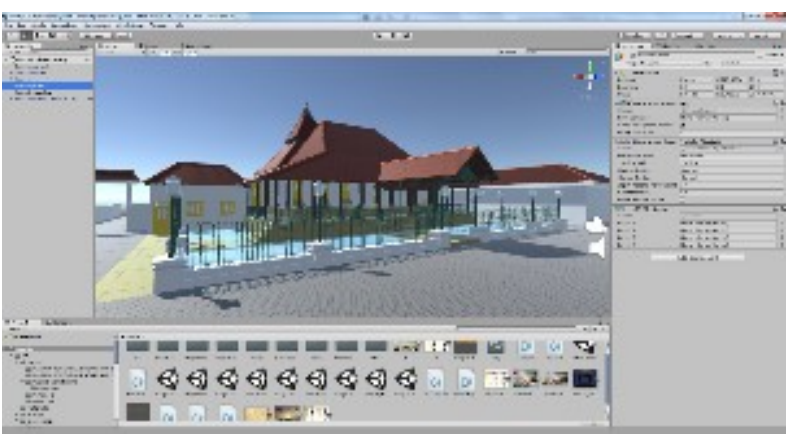

Figure 3.9. Imported Sketchup 3D Model of Plosokuning Mosque in Unity3D (Researcher, 2018)

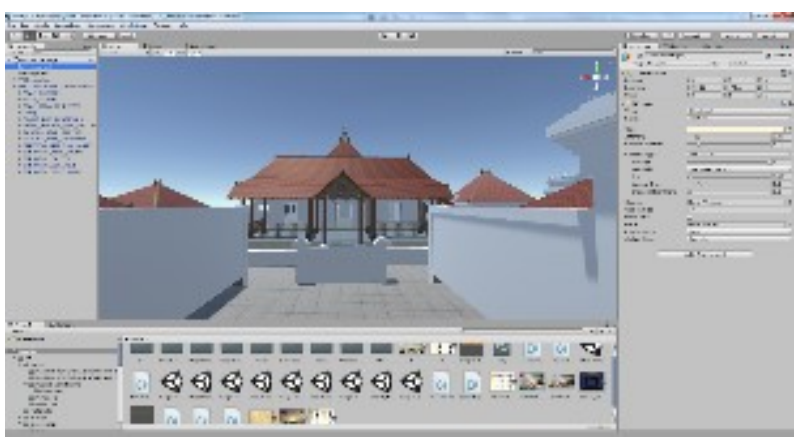

Figure 3.10. Imported Sketchup 3D Model of Mlangi Mosque in Unity3D (Researcher, 2018)

Immersion, interaction, imagination, and insight are keywords in the development of Virtual Reality applications according to Burdea \& Coiffet (2003). Further explained in his book, the immersion factor is about visual experience given to users. Interaction is about human interaction with a computer or application. Imagination is a factor that is given to virtual reality applications, giving an impact on users aiming to solve problems or convey specific ideas. Insight is to provide an in-depth understanding, both to groups of users and researchers.

The immersion factor in virtual reality applications raised in Figure. 3.11. in this research was carried out concerning audio and visual comfort. The virtual reality environment is equipped with supporting audio when the application is run and when explaining the mosque's initial history, namely an explanation of the history of the Pathok Negoro mosque recorded in the Indonesian language. Visual comfort is done by placing the camera controller at an average human eye height of 1.6 meters. The next effort to create visual comfort is to apply the use of natural lighting to buildings to bring up architectural characteristics.

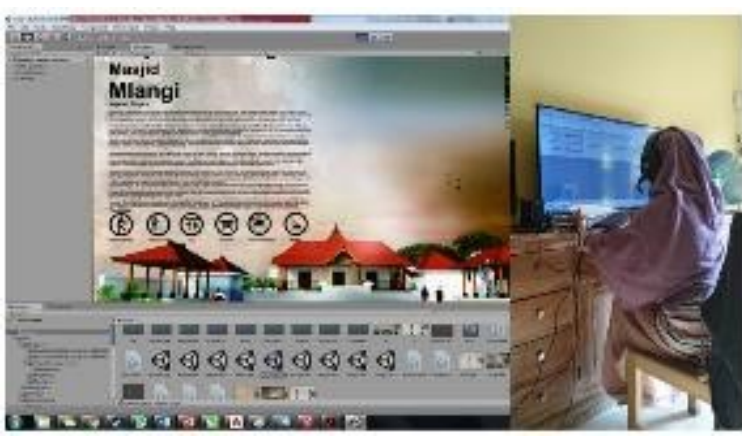

Figure 3.11. Creating Audio Visual of Pathok Negoro Mosque History (Researcher, 2018)

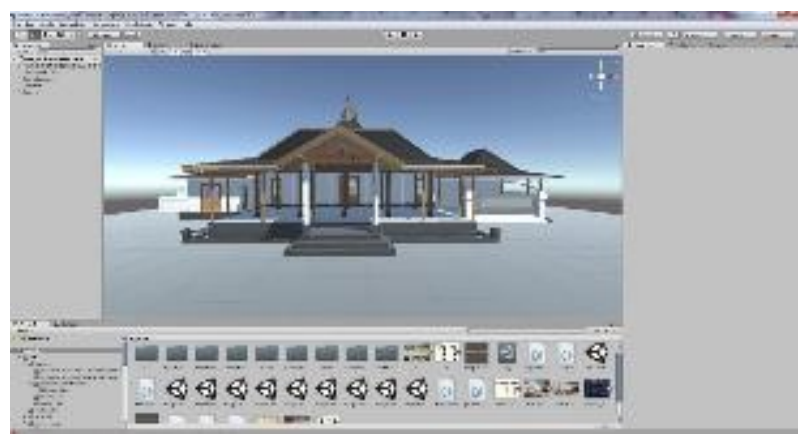

Figure 3.12. Interpretation of the Old Time Dongkelan Mosque (Researcher, 2018)

Furthermore, interaction is applied to the interaction process against the object of the construction of the Pathok Negoro mosque, namely applying the laws of physics by inserting gravity into it. Users can run at speeds that are adjusted and interact with 3D objects in a virtual reality environment. Moreover, the interaction of Dongkelan Mosque shown in Figure. 3.13 and 3.14. Figure 3.13 shows a short history of Dongkelan mosque and front building as cover, at the bottom of the page, there are two choices of building age era to pick using a mouse click. Figure 3.14. Shows gameplay of the latest condition of Dongkelan mosque, the user can use the keyboard arrow to walk and mouse to view panning. 


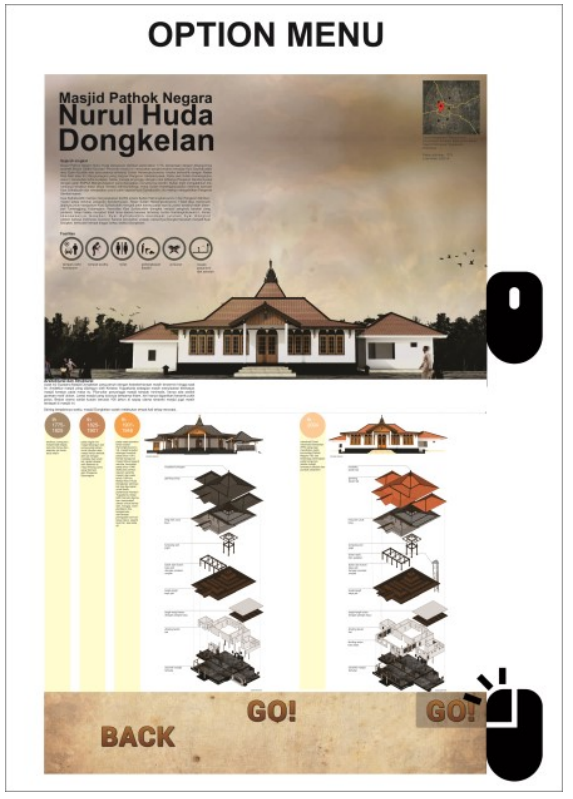

Figure 3.13. Options Menu on Virtual Reality Applications Interaction of The Dongkelan Mosque (Researcher, 2018)

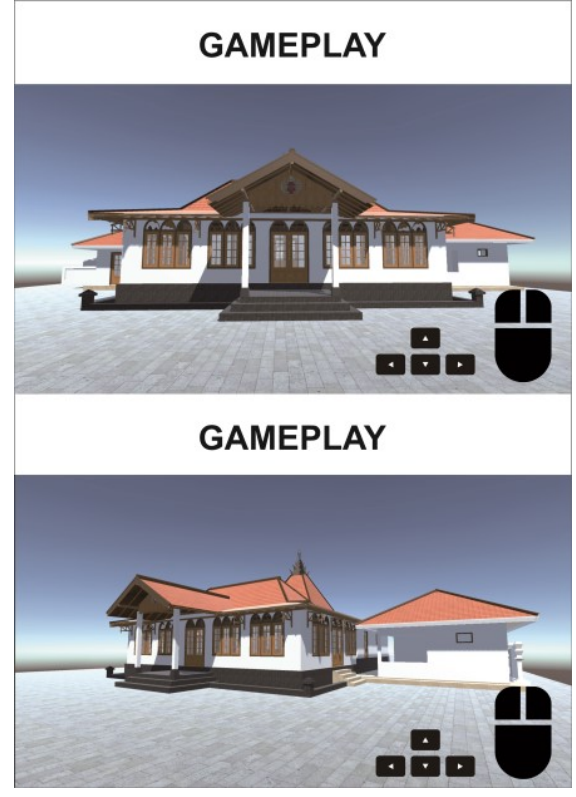

Figure 3.14. Gameplay on Virtual Reality Applications Interaction of The Dongkelan Mosque (Researcher, 2018)

The imagination factor is raised in Figure. 3.12 giving a picture of the past Dongkelan mosque and reveals historical documents of the Pathok Negoro Mosque. This imagination factor is by Deggim, Kersten, Tschirschwitz, \& Hinrichsen (2017), namely by giving six choices of the period of a city in its virtual reality application.

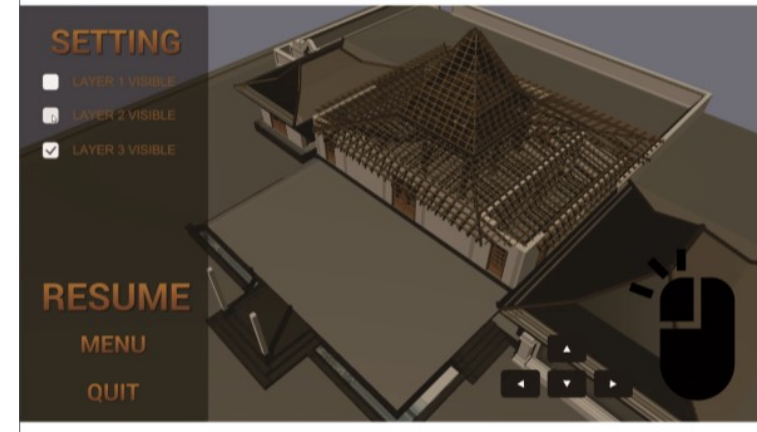

Figure 3.15. Layer Features on Virtual Reality Applications Interpretation of The Dongkelan Mosque (Researcher, 2018)

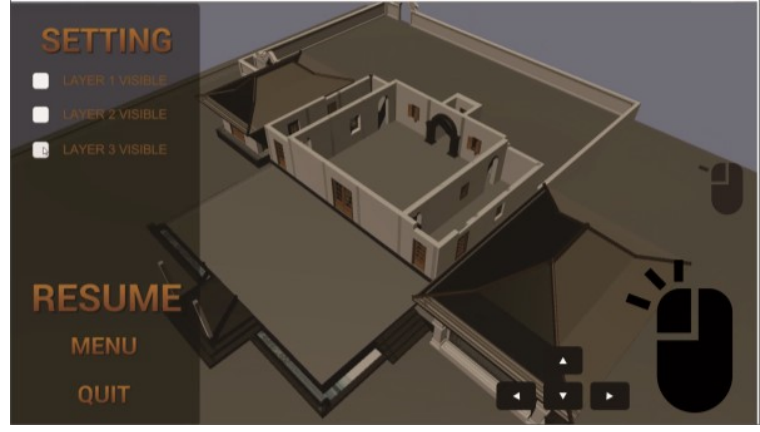

Figure 3.16. Set Layer Object Off on Virtual Reality Applications Interpretation of The Dongkelan Mosque (Researcher, 2018)

Insight into this virtual reality application is by providing navigation features as in Figure. 3.15 and 3.16 so that users can understand the characteristics of the architecture, structure, and history of the building of the Pathok Negoro mosque. The user interfaces Figure. 3.17 and 3.18 of the menu system, where users can start, see credit, or exit. Also, the user can choose the desired mosque after clicking Start. There are six mosque choices, as shown in Figure 3.18. The user uses the mouse click to operate the system. Figure 3.19. shows the credit of the application. 


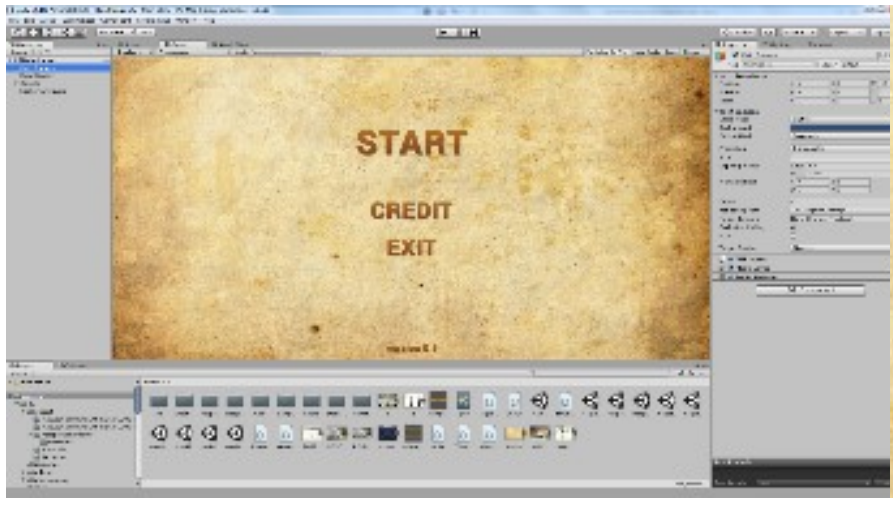

Figure 3.17. User Interface on Virtual Reality Applications (Researcher, 2018)

\section{DONGKELAN}

WONOKROMO

BABADAN

GEDHE KAUMAN

PLOSOKUNING

MLANGI

BACK

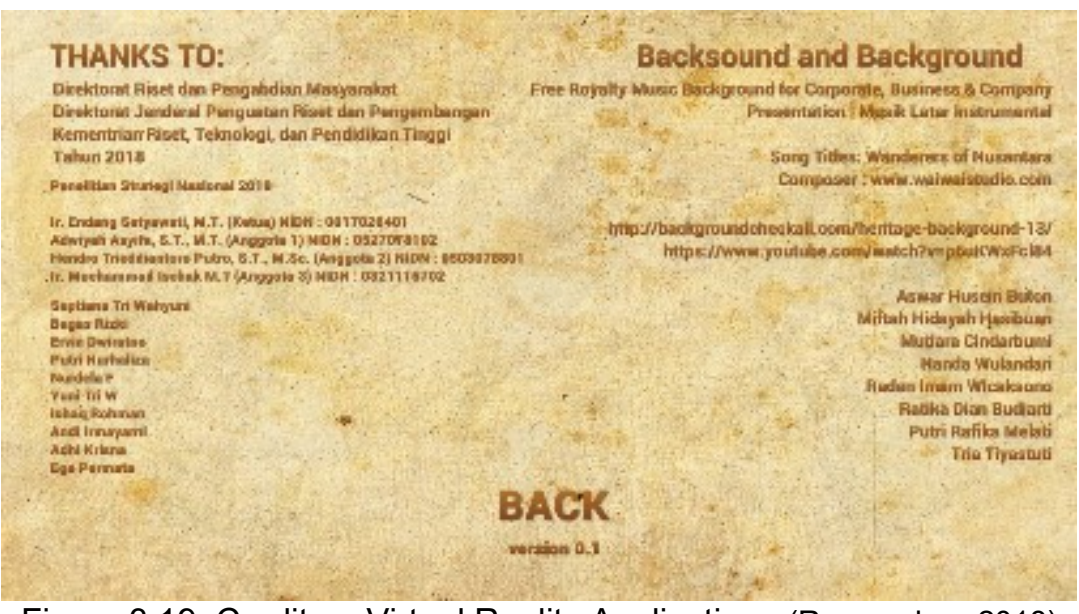

Figure 3.19. Credit on Virtual Reality Applications (Researcher, 2018)

The obstacles experienced by researchers in the process of making virtual reality applications is the time consuming for detail 3D modeling and the requirement for performance of computer devices, thus requiring devices with higher specifications in the graphics card section. The high demand for these devices is explained in the article by Ohannessian (2015), he said that the minimum specifications for Virtual Reality are high, mainly because Virtual Reality simulations require high frame rates or high frames per second to create smooth movement. Also, this relates to efforts to prevent the effects of simulation sickness on its users.

The benefit of this research approaches of digital conservation is using virtual reality to preserve the past as Michael Danti of the Syrian Heritage Initiative at the American Schools of Oriental Research said that technologies could be used not only to document the making and unmaking of heritage but both materially and in the imagination. ${ }^{1}$

\section{Conclusion}

The research succeeded in applying Virtual Reality technology to document the tangible and intangible features of the historical building of the Pathok Negoro Mosque. This study summarizes the process or steps for making a virtual reality application as well as the problems encountered during manufacture. The research objects are arranged in the form of real data and then redrawn in two and three dimensions to be included in the Unity3D program.

\footnotetext{
${ }^{1} \mathrm{http}$ //theconversation.com/museums-are-using-virtual-reality-to-preserve-the-past-before-its-too-late-44600
} 
The results of this study are Virtual Reality applications that can be operated and show the artificial environment with an immersive, interactive, insightful, and imagination of the Pathok Negoro Mosque. The immersion factor in virtual reality applications is raised concerning audio and visual comfort. The virtual reality environment is equipped with background audio and recorded sound for explaining the early history of the mosque, which is an explanation of the history of the Pathok Negoro mosque that recorded in the Indonesian language. Visual comfort is done by placing the camera at an average human eye height of 1.6 meters and applying natural lighting to buildings to bring out architectural characteristics. The interaction factor is applied to the process of interaction with the object of the Pathok Negoro Mosques building, namely applying the laws of physics by entering gravity and walking speed. The factor of imagination is raised by displaying 3D images of the past Pathok Negoro Mosques and giving rise to historical documents of the Pathok Negoro Mosques. The Insight factor in this virtual reality application is by providing navigation features so that users can understand the architectural characteristics, structure, and meanings that exist in the Pathok Negoro mosque building as a whole. However, there is still plenty of room for application development, such as multi-platform option and changing language background audio within the interaction.

The challenge encountered during the research was making the details of the ornaments and the color of the material at the stage of the 3D model. The interpretation technique that used was not a suitable method because it is time-consuming and lacks 3D modeling skill. Technical difficulties were in the preparation stage of the research tool, especially the computers used needed a high graphics card. Moreover, this research opens extensive opportunities for researchers in academics and practitioners such as historians, humanists, psychologists, and architecture especially in the field of preservation using digital media, space perception, and simulations of human interaction with computers.

\section{Acknowledgments}

The Acknowledgment is addressed to The Ministry of Research, Technology, and Higher Education of Republic Indonesia. Also University Technology of Yogyakarta.

\section{References}

Albourae, A. T., Armenakis, C., \& Kyan, M. (2017). Architectural Heritage Visualization Using Interactive Technologies. The International Archives of the Photogrammetry, Remote Sensing and Spatial Information Sciences, 7-13.

Burdea, G. C., \& Coiffet, P. (2003). Virtual reality technology (2nd ed). NJ: John Wiley \& Sons, Inc.

Campbell, S. (2017). A Rift in Our Practices?: Toward Preserving Virtual Reality. New York University, Department of Cinema Studies. New York: New York University.

Çizel, B., Ajanovic, E. (2018). Virtual Reality for Cultural Heritage Tourism. Culture, Heritage and Tourism Development, page 131-134, University Singidunum, Belgrade. DOI: 10.15308 / Sitcon-2018-131-134

Cohen, Nahoum, (2001). Urban Planning - Conservation and Preservation, Mc Graw Hill Book, Co., New York.

Daniel A. Guttentag, (2010), Virtual-Reality: Applications and implications for tourism, Journal Tourism Management, homepage: www.elsevier.com/locate/tourman.

Deggim, S., Kersten, T. P., Tschirschwitz, F., \& Hinrichsen, N. (2017). SEGEBERG 1600 Reconstructing A Historic Town For Virtual Reality Visualisation As An Immersive Experience. The International Archives of the Photogrammetry, Remote Sensing and Spatial Information Sciences, 87-94.

Lasa HS. (2009). Kamus Kepustakawanan Indonesia. Yogyakarta: Pustaka Book Publisher. 
Mihelj, M., Novak, D., \& Beguš, S. (2014). Virtual Reality Technology and Applications (Vol. 68). (S. G. Tzafestas, Ed.) New York, London: Springer.

Ohannessian, K. (2015, May 18). Oculus Rift's PC Requirements Are Virtual Reality's Achilles' Heel. Retrieved July 23, 2015, from Tech Forecast: http://www.fastcompany.com/3046376/tech-forecast/oculus-rifts-pc-requirements-arevirtual-realitys-achilles-hee

Putro, H. T. (2015). Immersive Virtual Reality for Tourism and Creative Industry Development. The 3rd International Conference on Creative Industry (pp. 380-385). Bali: Institut Teknologi Sepuluh Nopember. Retrieved from http://eprints.uty.ac.id/2855/

Putro, H. T. (2018). Virtual Reality as a Represent of Spatial Perception of Main Chapel Room at the Church of Light. ARSITEKTURA, Vol 16(2), Page 211-218. doi:http://dx.doi.org/10.20961/arst.v16i2.22636

R.Hassan.(2016).Virtual Reality as a Tool for Reconstruction and Documentation of Cultural Heritage Sites and Historically Important Landscape in Palestine. NLA Hostkonferanse, Oslo, 21 October 2016 "Landscape and Belonging"

S. Ghadban, R. Hassan, O. Aboudi, and Y. Khateeb. (2013). The Development Of An Interactive Virtual Environment For Hisham Palace In Jericho, Palestine. International Journal of Architectural Research. Archnet-IJAR, Volume 7 - Issue 2 - July 2013 - (118135) Đ Regular Section.

W. B. Yang, Y. N. Yen, H. M. Cheng. (2015). Digitalized Preservation And Presentation Of Historical Building -Taking Traditional Temples And Dougong As Examples. ISPRS Annual of the Photogrammetry, Remote Sensing and Spatial Information Sciences, Volume II-5/W3, 2015 25th International CIPA Symposium 2015, 31 August - 04 September 2015, Taipei, Taiwan. 